Investing in mutual funds: Does it pay to be a sinner or a saint in times of crisis?

\author{
Nelson Areal ${ }^{(*)}$ \\ nareal@eeg.uminho.pt \\ Maria Ceu Cortez ${ }^{(*)}$ \\ mccortez@eeg.uminho.pt \\ Florinda Silva ${ }^{(*)}$ \\ fsilva@eeg.uminho.pt
}

\title{
September 2010
}

\begin{abstract}
We investigate the performance of US socially responsible funds that employ different stock selection criteria: religious, social and 'irresponsible' criteria. Performance is evaluated over different market regimes using a Markov-switching conditional CAPM model that defines different states of the market endogenously. The 'irresponsible' fund outperforms in low volatility regimes, but underperforms in high volatility regimes. Furthermore, the risk of the 'irresponsible' fund is higher in low volatility regimes and lower in high volatility regimes. Socially responsible funds do not adjust risk according to market conditions. These findings suggest that socially responsible companies might provide better investments during periods of crisis.
\end{abstract}

Keywords:Socially responsible mutual funds; Vice fund; Fund performance evaluation; Market regimes; Markov-switching conditional CAPM

JEL Classification: G10, G11, M14

(*) NEGE - University of Minho

Campus de Gualtar, 4710-057 Braga, Portugal

Tel: +351253604554

Fax: +351253601380 


\title{
Investing in mutual funds: Does it pay to be a sinner or a saint in times of crisis?
}

\begin{abstract}
We investigate the performance of US socially responsible funds that employ different stock selection criteria: religious, social and 'irresponsible' criteria. Performance is evaluated over different market regimes using a Markov-switching conditional CAPM approach that defines different states of the market endogenously. The 'irresponsible' fund outperforms in low volatility regimes, but underperforms in high volatility regimes. Furthermore, the risk of the 'irresponsible' fund is higher in low volatility regimes and lower in high volatility regimes. Socially responsible funds do not adjust risk according to market conditions. These findings suggest that socially responsible companies might provide better investments during periods of crisis.
\end{abstract}

\section{Introduction}

There has been an ongoing debate on the performance of socially responsible investments, most of which focusing on whether it is possible to consider social issues without sacrificing financial performance. Theoretically, there are two conflicting arguments that explain the effects of incorporating social screens in the financial performance of investment portfolios. On the one hand, arguments based on modern portfolio theory suggest that any portfolio constructed on the basis of a reduced universe of stocks will suffer from diversification losses (Rudd, 1981). Furthermore, social portfolios incur in additional costs of monitoring social performance. Altogether, this will cause underperformance of socially screened portfolios compared to conventional portfolios. On the other hand, supporters of socially responsible investments claim that companies with high levels of corporate social responsibility perform better relative to less responsible companies. Hence, portfolios composed of stocks of socially responsible companies will yield enhanced performance (e.g. Hill et al., 2007; Kempf and Osthoff, 2007).

Empirical evidence on socially responsible funds has typically focused on the performance of these funds relatively to conventional benchmarks and funds. In general, it has been shown that there are no statistical differences between the performance of these funds and their conventional counterparts (Bauer et al., 2005; Bauer et al., 2006; Bauer et al., 2007; Gregory and Whittaker, 2007; Renneboog et al., 2008; and Cortez et al., 2009). This type of evidence has come in support of investors that wish to include their social concerns in their investment decisions as it suggests that it is possible to do well while doing good.

Socially responsible funds might use negative, positive, or best-in-class screens. Negative screens, typically used by the oldest generation of socially responsible mutual funds, exclude companies that are involved in activities that are considered "immoral" our "unethical", such as alcohol, gambling, armaments and tobacco. Positive filters aim for the inclusion of companies that are actively engaged in specific stakeholder-oriented issues, such as environment, community relations, employee relations, equal opportunities towards women and minorities. To avoid potential sector biases that may arise from applying negative screens, the best-in-class approach, which combines negative and positive criteria in each sector, has become increasingly popular. 
Furthermore, besides using different types of screens (positive, negative, or bestin-class), each fund may apply screens that vary according to a wide range of criteria. This raises the philosophical issue of defining what is a socially responsible fund and what falls into this category. Indeed, there is no consensus on the characteristics that award funds the label of "socially responsible". In its broadest definition, social investing would be any investment strategy based upon identifiable non-financial criteria (Dunfee, 2003). Accordingly, any non-financial criteria used in selecting stocks (even if unethical or irresponsible) can fall under the umbrella of socially responsible investing. This definition of socially responsible investments may therefore include stock selection criteria that are contradictory or mutually exclusive (Dunfee, 2003). As such, the screening criteria used by socially responsible funds can be as diverse as the heterogeneity of investors' values that each socially responsible fund attempts to satisfy. ${ }^{1}$ In fact, it is not difficult to find companies that are considered as having high standards of social responsibility by some funds and that are socially undesirable by other funds. ${ }^{2}$ The same applies to socially responsible indices, which exhibit different compositions and different levels of social responsibility, as documented by Statman (2006).

Despite the wide variety of criteria and types of screens used by socially responsible funds, its impact on performance seems overlooked in the literature. Indeed, the typical approach in previous studies has involved comparing the performance of socially responsible funds as a whole relative to conventional funds, disregarding the fact that the former are not coherent in their social objectives and that not all dimensions of social responsibility are rewarded in the same way. Nevertheless, a few studies (Barnett and Salomon, 2006; Renneboog et al., 2008; and Lee et al., 2010) have tackled the type and intensity of social screens used as possible determinants of performance. Barnett and Salomon (2006) find a curvilinear relationship between the number of screens and risk-adjusted performance of US socially responsible funds. ${ }^{3}$ In contrast, Lee et al. (2010) do not find any relationship (linear or curvilinear) between screening intensity and performance. Besides the US, Renneboog et al. (2008) also include European and Asia-Pacific markets, having found that fund returns decrease with screening intensity on social and corporate governance criteria, but not on ethical, sin or environmental criteria. ${ }^{4}$ Furthermore, Barnett and Salomon (2006) and Renneboog et al. (2008) find that some dimensions of social responsibility are more linked to higher financial performance than others. This evidence is consistent with a strand of literature that suggests the existence of a relationship between specific dimensions of social responsibility and financial performance. For instance, high levels of social performance

\footnotetext{
1 Although historically the first filters used in socially responsible investing are of the religious type, most of current screens used by socially responsible mutual funds are of a social nature and involve issues that are on the current social agenda. There has been a general tendency over time for the appearance of mutual funds that employ stakeholder-oriented screens that are focused on the environment, labor practices, community relations, treatment of customers, minorities and women (Waddock and Graves, 2000).

2 As Statman states: “one person's taboo is another person's sacred cow” (Statman, 2000, p. 31).

${ }^{3}$ The curvilinear relationship reflects the fact that as the number of screens used by socially responsible funds increases, financial performance declines up to a point and then rebounds.

${ }^{4}$ Renneboog et al. (2008) classify screening criteria into four types: sin screens (e.g.: tobacco, gambling, gambling, weapons and pornography), ethical screens (which involve animal testing, abortion, genetic engineering, non-marital, Islamic and healthcare screens), corporate governance and social screens (related to corporate governance, business practice, community, labor diversity, labor relations, human rights and foreign operations) and environmental screens (related to nuclear, environment and renewable energy issues).
} 
in terms of labor relations (Waddock and Graves, 1997), community relations (Waddock and Graves, 2000; Simpson and Kohers, 2002) and environmental issues (Klassen and McLaughlin, 1996; King and Lenox, 2001; Konar and Cohen, 2001; and Salama, 2005) have been documented as having a positive impact on the firms' financial performance.

Considering this type of evidence, Galema et al. (2008) call attention to the fact that the empirical evidence documented in the literature may reflect the aggregation of different dimensions of social responsibility that may have different effects on performance. In this line of research, we argue that the heterogeneity in the types of screens and criteria of social responsibility employed by socially responsible funds must be considered when evaluating fund performance.

On the other hand, this controversy has been fuelled by some studies that claim that social responsible investors incur costs from screening out sin stocks. For instance, Fabozzi et al. (2008) show that sin stocks outperform the market. Hong and Kacperczyk (2009) also argue that activities which are considered socially irresponsible or "unethical" (e.g., tobacco, alcohol and gambling) can generate higher expected returns than others. This type of evidence has given support to the existence of the so-called sin funds. The debate on whether funds that include stocks that represent socially undesirable activities offer higher returns is further motivated by the results of Statman and Glushkov (2009), who find that the return advantage obtained by investing in socially responsible firms is largely offset by the return disadvantage that comes from excluding stocks of 'shunned' firms.

As far as we are aware of, there is only one fund that explicitly assumes itself as a socially irresponsible fund: the "Vice Fund". Chong et al. (2006) document a significant outperformance of the Vice Fund relative to its benchmark (the Domini Social Equity Fund). However, these results must be interpreted with caution, as a very short time period of analysis has been used. In addition, the traditional performance measures used control neither for investment style nor time-varying risk. By increasing the time period and controlling for investment style, Hoepner and Zeume (2009) observe no outperformance of the Vice Fund.

In this context, the contribution of this paper is threefold. First, we aim to investigate the performance of socially responsible funds that diverge in the category of social responsible criteria used. Indeed, we consider funds that have contradictory and even mutually exclusive strategies relatively to what they consider to be acceptable investments: funds that use religious screens, social screens and even unethical screens. As far as we are aware of, this is the first study that compares these three categories of socially responsible funds.

Second, we evaluate the performance of socially responsible funds over different states of the market. Studies on the performance of these funds have typically shown that there are no statistical differences between the performance of these funds and that of their conventional counterparts (Bauer et al., 2005; Gregory and Whittaker, 2007; and Cortez et al., 2009). These studies, however, do not distinguish fund performance over different market regimes. It can be argued that firms that are socially responsible should benefit from a reputation that protects them from stock price declines associated with crises. There are only very few studies that have addressed this issue directly (e.g. Schnietz and Epstein, 2005; and Jones et al., 2000). We consider this a major contribution of this paper.

Finally, we innovate by extending the Markov Switching Conditional CAPM of Abdymomunov and Morley (2009) to a performance evaluation context. The current literature on mutual funds recognizes that using models of performance evaluation that 
do not account for time-varying returns and risk can generate biased estimates of fund performance. The dynamic nature of market conditions and of fund managers' strategies would hardly comply with a constant risk model assumption. The conditional approach for evaluating fund performance, developed by Ferson and Schadt (1996), has dealt with the time-varying risk issue by incorporating public information variables into the models. The underlying motivation is that these public information variables are related to economic conditions and therefore proxy for the state of the economy. Our approach to deal with time varying risk is a different one. Rather than using public information variables to capture time-varying risk and performance, as conditional approaches typically do, we follow Abdymomunov and Morley (2009) and apply a MarkovSwitching specification to identify different market volatility regimes. Since market volatility is inversely related to market conditions, i.e., a low market volatility state is generally associated with bull markets and a high market volatility state is usually associated with a bear market, it is possible to use a definition of high and low volatility regimes as a proxy for bull and bear markets. Hamilton (1989) suggests a parsimonious model to endogenously define different market volatility regimes using a Markovswitching model. This method can be adapted to create a conditional CAPM measure of mutual fund performance across different market regimes. This will allow us to identify if mutual funds' risk and return is dependent on market regimes. Our approach contrasts with previous studies on fund performance as the definition of market regimes and the timing of risk variations does not depend on the use of exogenous variables, but it is driven directly from the data, this way avoiding data mining issues. Additionally, this method might also be able to deal directly with some econometric problems that plague performance evaluation studies such as the time-varying nature of volatility and nonnormality of returns.

The remainder of this paper is organized as follows. Section 2 outlines the methodology used to assess fund performance. Section 3 describes the data. The results of the empirical estimations are presented and discussed in Section 4. Finally, section 6 summarizes the main results and presents some concluding remarks.

\section{Methodology}

When betas are time varying, the standard ordinary least squares (OLS) regression model is misspecified and cannot be used to assess the fit of a conditional CAPM model. Additionally, when betas are correlated with time varying market risk premium, standard regression alphas and betas provide a poor estimate of the conditional alphas and betas.

Jagannathan and Wang (1996) demonstrate that the OLS alpha from test regressions for the unconditional CAPM - where alpha corresponds to the excess expected return for the portfolio beyond what is predicted by the unconditional CAPM is theoretically related to the covariance between time-varying beta and the conditional market risk premium.

If we relax the assumption that CAPM beta is constant over time, it follows that (Jagannathan and Wang, 1996):

$$
E\left[R_{i, t} \mid I_{t-1}\right]=\alpha_{t-1}+\beta_{i, t-1}\left(R_{m, t-1}\right)
$$

where $E\left[R_{i, t} \mid I_{t-1}\right]$ is the conditional risk premium of portfolio $i$ at time $t$ given the information available at time $t-1$, and $R_{m, t-1}$ is the market risk premium at time $t-1$. This expression is equivalent to the unconditional multifactor model: 


$$
E\left[R_{i, t}\right]=\alpha^{c}+\operatorname{cov}\left(\beta_{i, t}, E\left[R_{m, t-1}\right]\right)+E\left[\beta_{i, t-1}\right] E\left[R_{m, t-1}\right]
$$

If the unconditional risk premium is uncorrelated with the expected beta then the relation resembles the unconditional multifactor CAPM. However, when the conditional betas and market risk premium are correlated, then OLS fails to provide consistent estimates of both the conditional alpha $\left(\alpha^{c}\right)$ and conditional betas.

Various studies present some evidence of the time varying nature of CAPM beta (Jagannathan and Wang, 1996; Lettau and Ludvigson, 2001; Fama and French, 2006; Lewellen and Nagel, 2006; Ang and Chen, 2007; Abdymomunov and Morley, 2009). Jagannathan and Wang (1996), Lettau and Ludvigson (2001) and Abdymomunov and Morley (2009), among others, argue that capturing this covariance through time-varying betas can help to explain size and/or book-to-market anomalies.

One way of assuming the conditional nature of the CAPM risk measure is to use a Markov-switching specification for the conditional CAPM. The use of a Markov switching conditional CAPM has several advantages. First, it defines endogenously the market regimes avoiding the use of instrumental variables and any data mining concerns associated with it. Secondly, many studies (e.g. Kim et al., 1998; Kim et al., 2001 and 2004) have already shown that a Markov-switching specification is appropriate to capture the stylized facts of monthly returns.

We follow a Markov-switching specification suggested by Hamilton (1989) of a conditional CAPM model proposed by Abdymomunov and Morley (2009). They use the market volatility regimes as a proxy for market economic conditions. There is a known inverse relation between market volatility and returns: high volatility periods are associated with negative returns, and low volatility periods are associated with positive returns. This means that market volatility regimes can be used as a proxy for bull and bear market conditions.

Abdymomunov and Morley (2009) define market conditions by a two state market excess return $\left(R_{m, t}\right)$ volatility regimes, given by:

$$
R_{m, t}=\left\{\begin{array}{cc}
\mu_{0}+\varepsilon_{t, 0} & \varepsilon_{t, 0} \sim N\left(0, \sigma_{0}^{2}\right) \\
\mu_{1}+\varepsilon_{t, 1} & \varepsilon_{t, 1} \sim N\left(0, \sigma_{1}^{2}\right)
\end{array}\right.
$$

which can be written as:

$$
R_{m, t}=\mu_{m, 0}+\mu_{m, 1} S_{m, t}+\varepsilon_{t} \quad \varepsilon_{t} \sim N\left(0, \sigma_{S_{m, t}}^{2}\right)
$$

where $\mu_{m, 0}$ denotes expected market excess return in low volatility regimes and $\mu_{m, 1}$ the marginal effect on expected return of high volatility regimes, and $S_{m, t}$ is the Markovswitching state variable.

To allow betas to be correlated with time varying market risk premium Abdymomunov and Morley (2009) also consider two betas, one for each regime. The two regime conditional CAPM is then given by:

$$
\begin{gathered}
E\left[R_{m, t} \mid S_{m, t}\right]=\mu_{m, 0}+\mu_{m, 1} S_{m, t} \\
E\left[R_{i, t} \mid S_{m, t}\right]=\beta_{i, S_{m, t}} E\left[R_{m, t} \mid S_{m, t}\right]
\end{gathered}
$$


which can be written as:

$$
\begin{aligned}
& R_{m, t}=\mu_{m, 0}+\mu_{m, 1} S_{m, t}+\varepsilon_{t} \quad \varepsilon_{t} \sim N\left(0, \sigma_{S_{m, t}}^{2}\right) \\
& R_{i, t}=\alpha_{i, S_{m, t}}+\beta_{i, S_{m, t}} R_{m, t}+\delta_{t} \quad \delta_{t} \sim N\left(0, \sigma_{S_{i, t}}^{2}\right)
\end{aligned}
$$

In this model, the regimes are driven by the unobservable state variable $S_{m, t}$ which can assume two values: 0 and 1, for the market premium high volatility regime and for the low market premium volatility regime respectively:

$$
\begin{gathered}
\operatorname{Pr}\left[S_{m, t}=0 \mid S_{m, t-1}=0\right]=q_{m} \\
\operatorname{Pr}\left[S_{m, t}=1 \mid S_{m, t-1}=1\right]=p_{m}
\end{gathered}
$$

where $q$ and $p$ are the transition probabilities.

As Abdymomunov and Morley (2009), we control for the heteroscedasticity of fund premiums by allowing the $\delta_{t}$ to follow another two state Markov-switching volatility process which is independent of the market premium volatility states.

The likelihood of the Markov-switching model is evaluated using the filtering procedure of Hamilton (1990) followed by the smoothing algorithm of Kim (1994). The log likelihood function is maximized using the feasible non-linear programming approach suggested by Lawrence and Tits (2001).

The Markov-switching conditional CAPM model here considered has several advantages worthy of note. First, it is a parsimonious model which is easy to estimate and does not depend on exogenous definitions of market conditions. Additionally, at least for monthly returns there is usually no further heteroscedasticity or non-linear dependence. Finally, as Abdymomunov and Morley (2009) show, it may partially explain the non-market risk premiums, i.e. book-to-market and size anomalies.

\section{Data}

Our sample is composed by US equity socially responsible funds that employ distinct (and even contradictory) types of screens to define what they consider to be acceptable investments. In particular, we select the Vice Fund, the only socially 'irresponsible' fund that is committed to investing in activities that are usually considered undesirable (or sinful), such as: alcoholic beverages, tobacco, gambling and weapons. We have also considered funds that apply ethical criteria. These funds have been divided into two categories: morally responsible investment (MRI) funds, which are funds that employ religious screens (according to catholic, lutheran and islamic principles) and socially responsible investment (SRI) funds, which are funds that employ screens on the basis of a social rather than a religious agenda.

We identify funds from the Social Investment Forum and from funds' prospectus. To be included in the sample, funds were required to have at least 24 monthly observations. In total, the sample is composed of $13 \mathrm{MRI}$ and $38 \mathrm{SRI}^{5}$ funds from the US in addition to the Vice fund over the period October 1993 to September 2009. ${ }^{6}$

Both surviving and nonsurviving funds are included. Daily and monthly returns were collected from Datastream. Continuously compound returns are net of

\footnotetext{
${ }^{5}$ When considering monthly data only 37 SRF funds are considered as one of the funds has less than 24 monthly observations.

${ }^{6}$ The list of funds is presented in Appendix 1.
} 
management fees but gross of load fees. Excess returns are computed relative to the risk-free rate, proxied by the one-month Euro-Dollar deposit rate. The S\&P 500 is used as benchmark. For the Carhart (1997) 4-factor model, in addition to the S\&P500, we consider the value, size and momentum factors available in Kenneth French's website.

Table 1 reports the main descriptive statistics of our funds as well as of the benchmark. Equally weighted portfolios of all funds for the MRI and SRI categories are analyzed. As can be observed, MRI funds and SRI funds present lower mean excess returns comparable to those obtained by the Vice fund and the benchmark. Volatility seems to be similar across fund categories. All portfolios, including the benchmark, exhibit negative skewness and excess kurtosis. Normality is clearly rejected both for daily and monthly returns.

\section{[Insert Table 1 here]}

In order to apply the Markov-switching conditional CAPM, we start by identifying the high and low volatility market regimes based on the S\&P500 series. Figure 1 shows the daily evolution of the market index (S\&P 500) from October 1993 to September 2009. The grey areas identify the high volatility market regimes, while the areas in white correspond to low volatility market regimes. Figure 2 shows the daily excess returns of the market index over the same period. As can be observed, the Markovswitching model is able to correctly identify these two market regimes. The most pronounced market decreases correspond in most of the cases to periods of high volatility. Figures 3 and 4 show the different volatility market regimes when monthly series are considered. In comparison with daily data, we observe clearly less transitions between the two market regimes, as expected. Two high volatility periods are identified: the period from July 1993 to May 2003 and the period from November 2007 to the end of the sample period (September 2009). As shown in Figure 4, these two periods are characterized by highly negative market excess returns.

[Insert Figures 1 to 4 here]

\section{Empirical Results}

We start by analyzing fund performance using unconditional models. Both the CAPM and the Carhart (1997) 4-factor model are considered.

Table 2 presents CAPM-based performance estimates. The Vice fund exhibits a positive alpha, although it is not statistically significant. At the aggregate level, both MRI and SRI portfolios of funds show statistically negative underperformance, although at the individual fund level most of the funds present neutral performance. These results are robust to daily and monthly excess returns. Only two SRI and two MRI funds present statistically significant (at the 5\% level) negative alphas when daily excess returns are used. When monthly excess returns are used, one SRI fund shows a statistically significant positive alpha and one SRI fund and two MRI funds present statistically significant negative alphas. Of the four funds presenting underperformance on the basis of daily excess returns, three also show underperformance on the basis of monthly excess returns. The residuals of the regressions, however, are clearly nonnormal, a fact that might question the validity of parametric statistical inferences of the OLS performance estimates.

[Insert Table 2 here] 
The results of applying the Carhart (1997) 4-factor model are presented in Table 3. Performance estimates are similar at the portfolio level, although at the individual fund level there is a higher number of funds with statistically negative alphas: five SRI funds and four MRI funds when daily excess returns are used and the same nine funds plus one more MRI fund when monthly excess returns are used. The additional factors seem to be able to explain fund returns, particularly when daily data is used. Indeed, the size factor is an important factor for both SRI and MRI funds, either considering daily or monthly returns. The SRI portfolio of funds has a significant exposition to all three factors (value, size and momentum) while the MRI portfolio is more exposed to the size effect. In the case of the Vice fund, the additional factors seem to be important when daily excess returns are considered. However, they do not seem to be relevant when using monthly excess returns. We do not reject the Wald test on the hypothesis of these additional factors being equal to zero for this fund. Once more, tests on the OLS residuals reveal the econometric problems mentioned above: non-normality, autocorrelation and heteroscedasticity.

\section{[Insert Table 3 here]}

A possible explanation for the econometric problems uncovered might be associated to the fact that these methodologies do not account for time-variation of risk and performance across different states of the economy. We attempt to overcome these limitations by evaluating performance through a two regime Markov switching conditional CAPM model described in section 2. This model has the advantage of allowing performance and risk parameters to be time varying and directly deal with the heteroscedasticity of mutual fund risk premiums.

Table 4 presents the results of the Markov switching conditional CAPM (MSCCAPM) regressions. Performance estimates and risk are shown for periods of low and high volatility considering both daily and monthly returns. The evidence is remarkable for monthly returns. In this case, most of the econometric issues pointed out previously have been overcome. Consequently, the results in Panel B can be interpreted with higher reliability than those obtained before.

The evidence shows that funds' performance and risk estimates are clearly distinct across the two different market regimes. In particular, we observe that the Vice fund outperforms the market in low volatility markets, but underperforms in high volatility markets. In contrast, both portfolios of SRI and MRI funds seem to be better performers in high volatility markets.

Regarding risk estimates, a wide difference is observed for the Vice fund, which presents a higher beta in low volatility regimes and a lower beta in high volatility regimes. Although to a less extent, this evidence is also found for the MRI portfolio. In contrast, the SRI portfolio shows more stable betas across the two market regimes. The fact that socially responsible fund managers may be more constrained in terms of the security selection process may help to explain these results. SRI fund managers do not seem to adjust fund betas according to market conditions. Therefore, the better performance of the SRI portfolio in high volatility regimes might be a consequence of the characteristics of the underlying assets. This is consistent with the argument that stocks of socially responsible companies provide better investments during periods of crisis (e.g. Jones et al., 2000; Schnietz and Epstein, 2005).

[Insert Table 4 here] 
A potential problem in the inferences from the previous analysis is that we are measuring the fund performances of different types of funds over different periods. As the return series for the Vice fund is available only since September 2002, we repeated the estimation of the MS-CCAPM model considering the shorter period of September 2002 to October 2009..$^{7}$ Table 5 presents the results on the performance and risk estimates. ${ }^{8}$

\section{[Insert Table 5 here]}

As can be observed, the results obtained are very similar, showing that in this shorter period estimates of fund performance and risk change across the distinct market regimes. Also SRI and MRI funds tend to present better performance in high volatility regimes while the Vice fund underperforms in these market conditions.

Our findings seem to be quite robust and provide important insights to investors. Investment decisions taking into account diverse social and ethical/religious criteria may provide some insurance in times of crisis. Our results are also interesting as they contrast with a major claim of the Vice Fund, which is that irresponsible stocks are better performers in recessionary periods.

\section{Conclusions}

Empirical studies on the performance of socially responsible funds have typically involved comparing the performance of these funds as a whole relative to conventional funds. Although it has been recognized that not all dimensions of social responsibility are rewarded in the same way, the analysis of socially responsible fund performance according to the criteria and types of screens used is a topic hardly explored in the literature.

This paper contributes to fill this gap. We investigate the performance of socially responsible funds that use different types of filters in the security selection process. The sample includes US equity funds that invest according to religious criteria (MRI funds), social criteria (SRI funds) and 'irresponsible' criteria over the period of October 1993 to September 2009. Furthermore, the performance of these funds is analyzed over different market regimes, in order to assess whether socially responsible investments perform better in periods of crisis. Moreover, a Markov-switching conditional CAPM approach, suggested by Abdymomunov and Morley (2009) is used to identify endogenously market regimes. This model has the advantage of, while parsimonious, being able to deal with many econometrics problems that usually affect fund performance studies.

Estimates of fund performance obtained with the Markov switching conditional CAPM regressions are noticeable. Indeed, we document different alphas and betas for periods of high and low market volatility for the Vice fund, which outperforms the market and portfolios of socially responsible funds (both MRI and SRI) in low volatility regimes, but underperforms in periods of high volatility. Furthermore, risk estimates also change according to market conditions. The Vice fund exhibits a higher beta in low volatility regimes and a lower beta in high volatility regimes. Although to a less extent, this evidence is also found for the MRI portfolio. In contrast, the SRI portfolio exhibits similar betas across the two market regimes. These results suggest that SRI fund

\footnotetext{
${ }^{7}$ The different volatility market regimes over this shorter period are similar to those shown previously for the complete sample period.

${ }^{8} \mathrm{We}$ have repeated the analysis of fund performance based on the CAPM model and the 4-factor model for this shorter period. The results are very similar to those obtained for the global period and thus not reported.
} 
managers do not adjust fund betas according to market conditions. Therefore, the higher performance of the SRI portfolio in high volatility periods might be a consequence of the characteristics of the underlying assets. This is consistent with the argument that stocks of socially responsible companies provide better investments during periods of crisis.

The fact that the implementation of the Markov-switching conditional CAPM overcomes most of the econometric problems inherent to the standard performance evaluation methodologies allows our results to be interpreted with a higher degree of confidence. Yet, the fact that there is only one fund that considers 'irresponsible' criteria implies some caution. The issue of whether socially screened portfolios generate a better performance comparatively to conventional portfolios remains unsolved and deserves further research.

\section{References}

Abdymomunov, A. and J. C. Morley (2009), 'Time variation of CAPM betas across market volatility regimes for book-to-market and momentum portfolios', Working Paper, available at http://artsci.wustl.edu/ morley/am.pdf

Ang, A. and J. Chen (2007), 'CAPM over the long run: 1926-2001', Journal of Empirical Finance, Vol. 14, No. 1, pp. 1-40.

Barnett, M. L. and R. M. Salomon (2006), 'Beyond dichotomy: the curvilinear relationship between social responsibility and financial performance', Strategic Management Journal, Vol. 27, No. 11, pp. 1101-1122.

Bauer, R., J. Derwall, and R. Otten (2007), 'The ethical mutual fund performance debate: new evidence from Canada', Journal of Business Ethics, Vol. 70, No. 2, pp. 111-124.

Bauer, R., K. Koedijk and R. Otten (2005), 'International evidence on ethical mutual fund performance and investment style', Journal of Banking and Finance, Vol. 29, No. 7, pp. 1751-1767.

Bauer, R., R. Otten and A. T. Rad (2006), 'Ethical investing in Australia: Is there a financial penalty?', Pacific-Basin Finance Journal, Vol. 14, No. 1, pp. 33-48.

Breusch, T. S. and A. R. Pagan (1979), 'A simple test for heteroscedasticity and random coefficient variation', Econometrica, Vol. 47, No. 5, pp. 1287-1294.

Chong, J., M. Her and G. M. Phillips (2006), 'To sin or not to sin? Now that's the question', Journal of Asset Management, Vol. 6, No. 6, pp. 406-417.

Carhart, M. (1997), 'On persistence in mutual fund performance', Journal of Finance, Vol. 52, No. 1, pp. 57-83.

Cortez, M. C., F. Silva and N. Areal (2009), 'The performance of European socially responsible funds', Journal of Business Ethics, Vol. 87, No. 4, pp. 573-588.

Cribari-Neto, F. (2004), 'Asymptotic inference under heteroskedasticity of unknown form', Computational Statistics and Data Analysis, Vol. 45, No. 2, pp. 215-233.

Doornik, J. A. and H. Hansen (1994), 'A practical test for univariate and multivariate normality', Working Paper (Nuffield College). 
Dunfee, T. W. (2003), 'Social investing: mainstream or backwater', Journal of Business Ethics, Vol. 43, No. 3, pp. 247-252.

Engle, R. F. (1982), 'Autoregressive conditional heteroscedasticity, with estimates of the variance of United Kingdom inflation', Econometrica, Vol. 50, No. 4, pp. 987-1007.

Fabozzi, F. J., K. C. Ma and B. J. Oliphant (2008), 'Sin stock returns', Journal of Portfolio Management, Vol. 35, No. 1, pp. 82-94.

Fama, E. and K. French (2006), 'The value premium and the CAPM', Journal of Finance, Vol. 61, No. 5, pp. 2163-2185.

Ferson, W. and R. Schadt (1996), 'Measuring fund strategy and performance in changing economic conditions', Journal of Finance, Vol. 51, No. 2, pp. 425-461.

Galema, R., A. Plantinga and B. Scholtens (2008), 'The stocks at stake: Return and risk in socially responsible investments', Journal of Banking and Finance, Vol. 32, No. 12, pp. 2646-2654.

Gregory, A and J. Whittaker (2007), 'Performance and performance persistence of 'ethical' unit trusts in the UK', Journal of Business Finance \& Accounting, Vol. 34, No. 7, pp. 1327-1344.

Hamilton, J. D. (1989), 'A new approach to the economic analysis of nonstationary time series and the business cycle', Econometrica, Vol. 57, No. 2, pp. 357-384.

Hamilton, J. D. (1990), 'Analysis of time series subject to changes in regime', Journal of Econometrics, Vol. 45, No. 1-2, pp. 39-70.

Hill, R. P., T. Ainscough, T. Shank and D. Manullang (2007), 'Corporate social responsibility and social responsible investing: a global perspective', Journal of Business Ethics, Vol. 70, No. 2, pp. 165-174.

Hong, H.G. and M. T. Kacperczyk (2009), 'The price of sin: The effects of social norms on markets', Journal of Financial Economics, Vol. 93, No. 1, pp. 15-36.

Hoepner, A. and S. Zeume (2009), 'The dark enemy of responsible mutual funds: does the Vice Fund offer more financial virtue?', Working paper available at SSRN: http://ssrn.com/abstract=1485846

Jagannathan, R. and Z. Wang (1996), 'The conditional CAPM and the cross-section of expected returns', Journal of Finance, Vol. 51, No. 1, pp. 3-53.

Jones, G. H., B. H. Jones and P. Little (2000), 'Reputation as a reservoir: buffering against loss in times of economic crisis', Corporate Reputation Review, Vol. 3, No. 1, pp. 21-29.

Kempf, A. and P. Osthoff (2007), 'The effect of socially responsible investing on portfolio performance', European Financial Management, Vol. 13, No. 5, pp. 908-922.

Kim, C. J. (1994), 'Dynamic linear models with markov switching', Journal of Econometrics, Vol. 60, No. 1-2, pp. 1-22.

Kim, C. J., J. C. Morley and C. R. Nelson (2001), 'Does an intertemporal tradeoff between risk and return explain mean reversion in stock prices?', Journal of Empirical Finance, Vol. 8, No. 4, pp. 403-426.

Kim, C. J., J. C. Morley and C. R. Nelson (2004), 'Is there a positive relationship between stock market volatility and the equity premium', Journal of Money, Credit, and Banking, Vol. 36, No. 3, pp. 339-360. 
Kim, C. J., C. R. Nelson and R. Startz (1998), 'Testing for mean reversion in heteroskedastic data based on Gibbs-sampling-augmented randomization', Journal of Empirical Finance, Vol. 5, No. 2, pp. 131-154.

King, A. A. and M. J. Lenox (2001), 'Does it really pay to be green? An empirical study of firm environmental and financial performance', Journal of Industrial Ecology, Vol. 5, No. 1, pp. 105-116.

Klassen, R. D. and C. P. McLaughlin (1996), 'The impact of environmental management on firm performance', Management Science, Vol. 42, No. 8, pp. 199-1214.

Konar, S. and M. Cohen (2001), 'Does the market value environmental performance?', Review of Economics and Statistics, Vol. 83, No. 2, pp. 281-309.

Lawrence, C. T. and A. L. Tits (2001), 'A computationally efficient feasible sequential quadratic programming algorithm', SIAM Journal of Optimization, Vol. 11, No. 4, pp. 1092-1118.

Lee, D. D., J. E. Humphrey, K. L. Benson and J. Y. K. Ahn (2010), 'Socially responsible investment fund performance: the impact of screening intensity', Accounting and Finance, Vol. 50, No. 2, pp. 351-370.

Lettau, M. and S. Ludvigson (2001), 'Resurrecting the (C)CAPM: A cross-sectional test when risk premia are time-varying', Journal of Political Economy, Vol. 109, No. 6, pp. 1238-1287.

Lewellen, J. and S. Nagel (2006), 'The conditional CAPM does not explain assetpricing anomalies', Journal of Financial Economics, Vol. 82, No. 2, pp. 289-314.

Newey, W. K. and K. D. West (1994), 'Automatic lag selection in covariance matrix estimation', The Review of Economic Studies, Vol. 61, No. 4, pp. 631-653.

Renneboog, L., J. T. Horst, and C. Zhang (2008), 'The price of ethics and stakeholder governance: The performance of socially responsible mutual funds', Journal of Corporate Finance, Vol. 14, No. 3, pp. 302-322.

Rudd, A. (1981), 'Social responsibility and portfolio performance', California Management Review, Vol. 23, No. 4, pp. 55-61.

Salama, A. (2005), 'A note on the impact of environmental performance on financial performance', Structural Change and Economic Dynamics, Vol. 16, No. 3, pp. 413-421.

Schnietz, K. E. and M. J. Epstein (2005), 'Exploring the financial value of a reputation for corporate social responsibility during a crisis', Corporate Reputation Review, Vol. 7 , No. 4, pp. 327-345.

Simpson, W. G. and T. Kohers (2002), 'The link between corporate social and financial performance: evidence from the banking industry', Journal of Business Ethics, Vol. 35, No. 2, pp. 97-109.

Statman, M. (2000), 'Socially responsible mutual funds', Financial Analysts Journal, Vol. 56, No. 3, pp. 30-39.

Statman, M. (2006), 'Socially responsible indexes: composition, performance and tracking error', Journal of Portfolio Management, Vol. 32, No. 3, pp. 100-109.

Statman, M. and D. Glushkov (2009), 'The wages of social responsibility', Financial Analysts Journal, Vol. 65, No. 4, pp. 33-46. 
Waddock, S. and S. Graves (1997), 'The corporate social performance - financial performance link', Strategic Management Journal, Vol. 18, No. 4, pp. 303-319.

Waddock, S. and S. Graves (2000), 'Performance characteristics of social and traditional investments', Journal of Investing, Vol. 9, No. 2, pp. 27-38.

White, H. (1980), 'A heteroskedasticity-consistent covariance matrix estimator and a direct test for heteroskedasticity', Econometrica, Vol. 48, No. 4, pp. 817-838. 
Figure 1 - S\&P500 daily evolution over the period October 1993 to September 2009

The areas in grey identify high volatility regimes and the areas in white correspond to low volatility regimes.

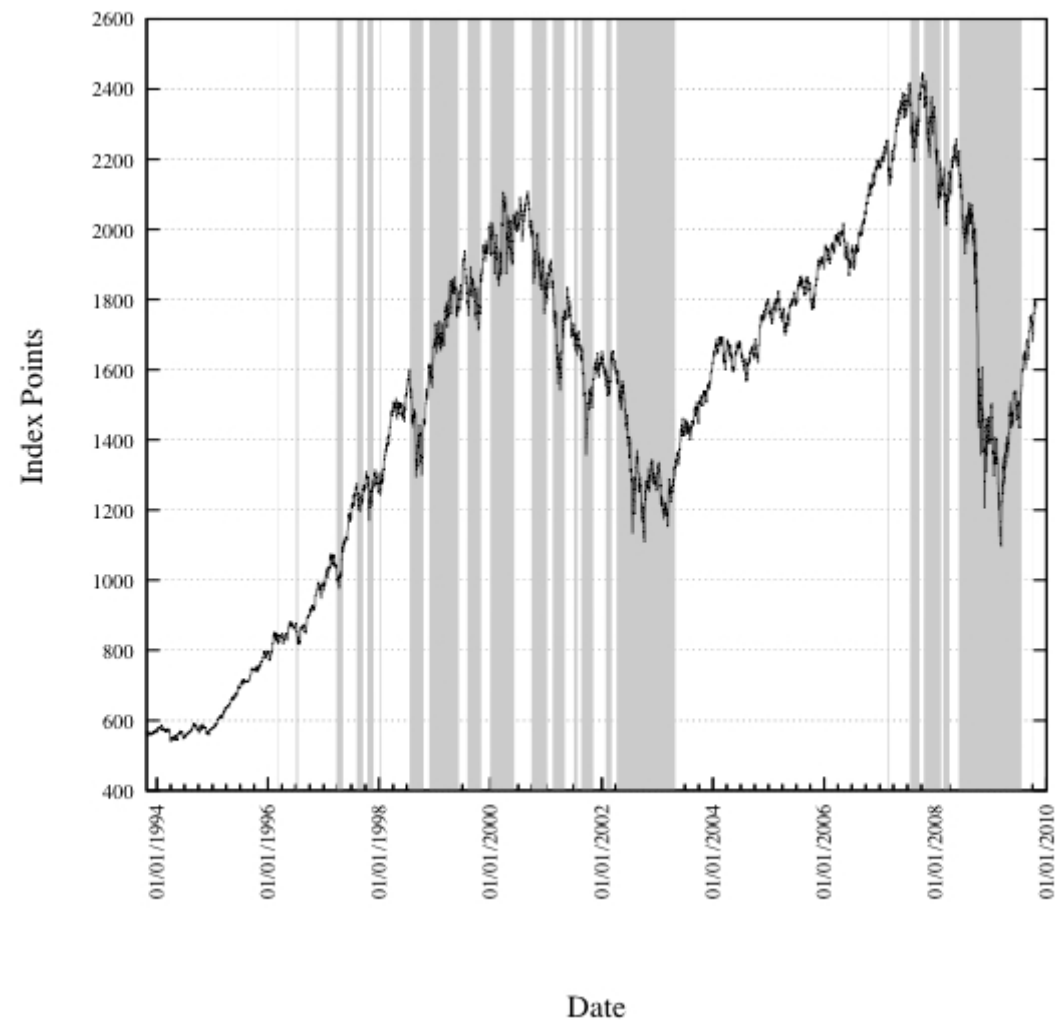

Figure 2 - S\&P500 daily excess returns over the period October 1993 to September 2009 The areas in grey identify high volatility regimes and the areas in white correspond to low volatility regimes.

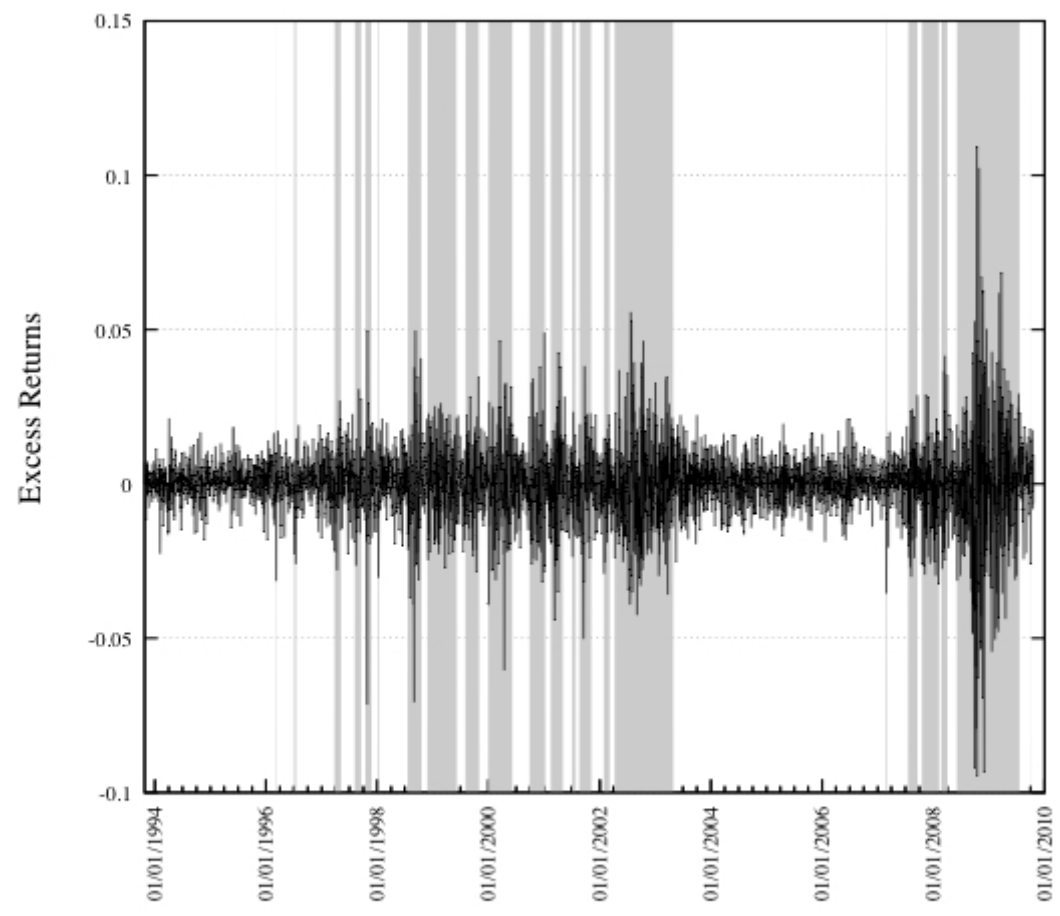

Date 
Figure 3 - S\&P500 monthly evolution over the period October 1993 to September 2009

The areas in grey identify high volatility regimes and the areas in white correspond to low volatility regimes.

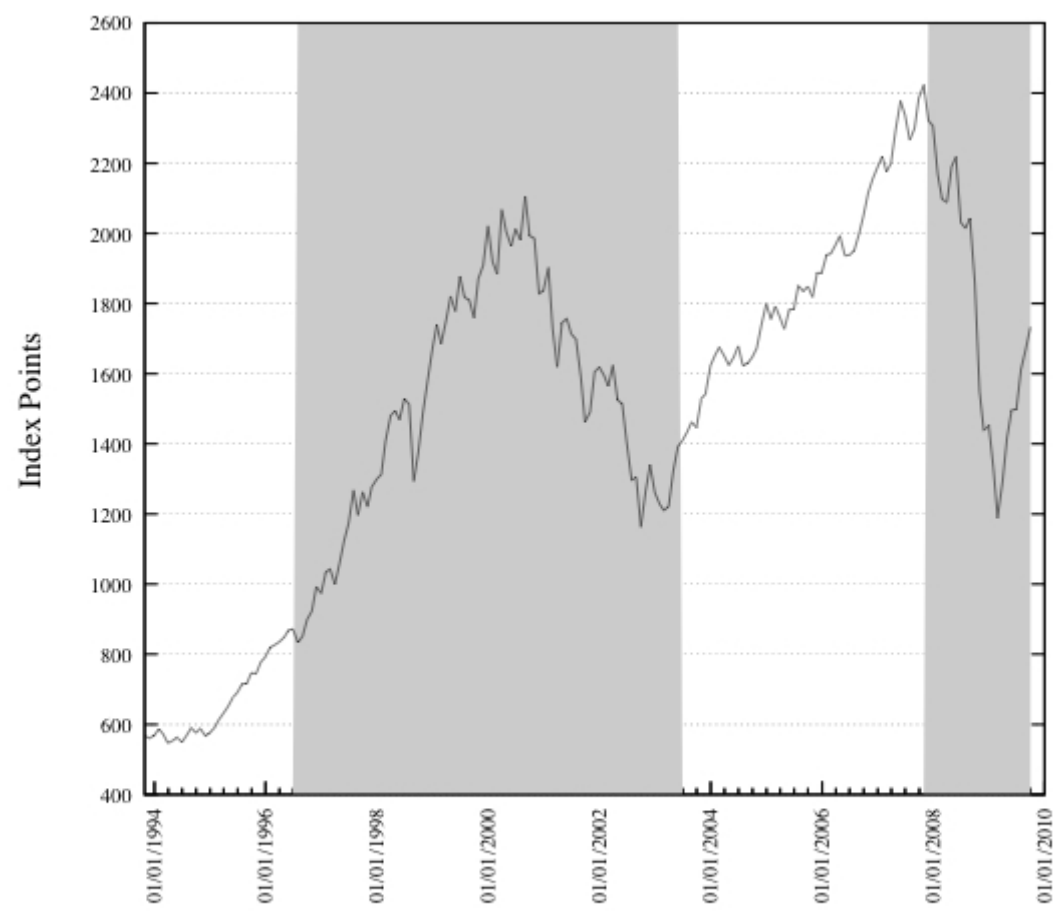

Date

Figure 4 - S\&P500 monthly excess returns over the period October 1993 to September 2009

The areas in grey identify high volatility regimes and the areas in white correspond to low volatility regimes.

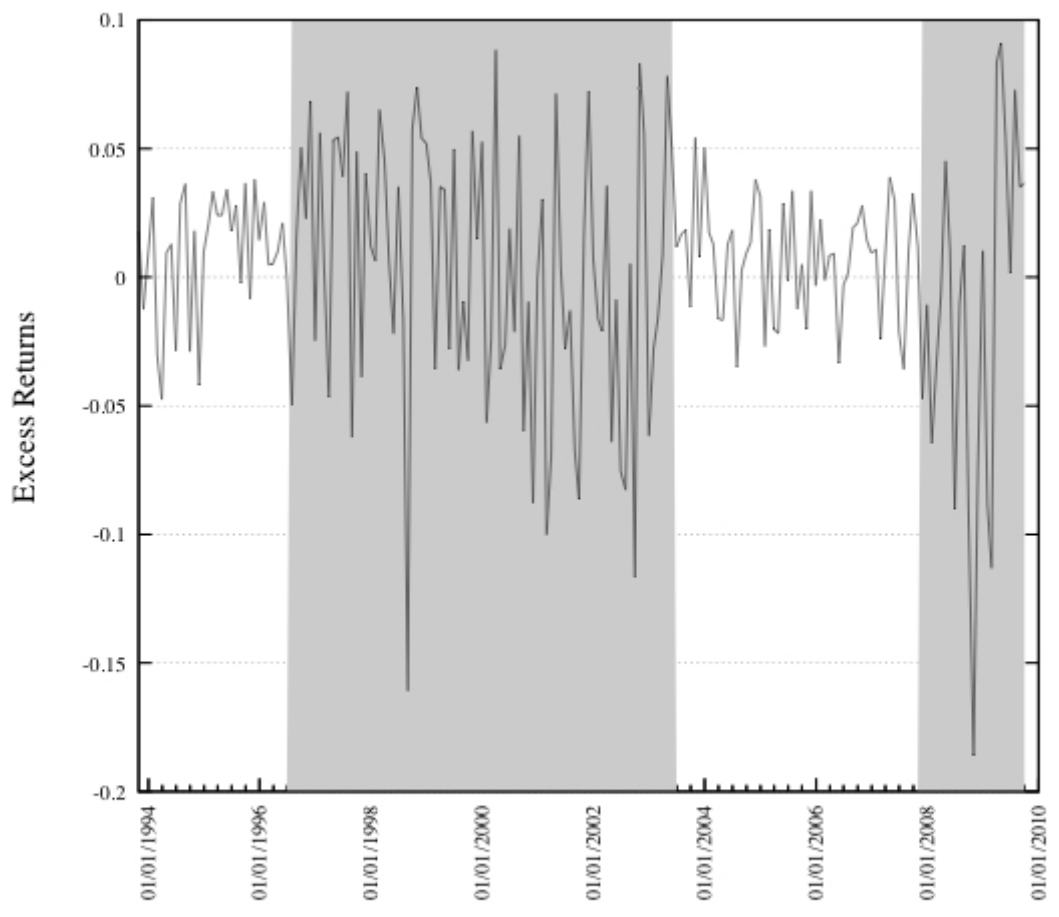

Date 


\section{Table 1 - Summary statistics on fund portfolios and benchmark}

This table reports summary statistics for the Vice fund as well as for the equally weighted portfolios of SRI and MRI funds and for the S\&P500 index over the period October 1993 to October 2009. Panel A refers to statistics based on daily excess returns and Panel B to statistics based on monthly excess returns. Annualized mean excess returns and standard deviation, expressed in percentage, and results on the skewness, kurtosis, Jarque Bera test and the minimum and maximum excess returns are presented.

\begin{tabular}{|c|c|c|c|c|c|c|c|c|c|c|c|}
\hline & № Obs. & Start date & End date & Mean & SD & Skewness & Kurtosis & JB test & JB prob. & Min & Max \\
\hline \multicolumn{12}{|c|}{ PANEL A - Daily excess returns } \\
\hline VICE fund & 1852 & $16 / 09 / 2002$ & 20/10/2009 & 3.275 & 16.888 & -0.309 & 13.352 & 8299.338 & 0.000 & -0.082 & 0.096 \\
\hline SRI portfolio & 4171 & $26 / 10 / 1993$ & $20 / 10 / 2009$ & 0.100 & 17.698 & -0.320 & 11.664 & 13116.895 & 0.000 & -0.091 & 0.098 \\
\hline MRI portfolio & 4171 & $26 / 10 / 1993$ & $20 / 10 / 2009$ & -0.550 & 17.789 & -0.277 & 11.984 & 14080.026 & 0.000 & -0.089 & 0.101 \\
\hline S\&P500 & 4171 & $26 / 10 / 1993$ & $20 / 10 / 2009$ & 4.175 & 19.372 & -0.198 & 12.094 & 14399.548 & 0.000 & -0.095 & 0.109 \\
\hline \multicolumn{12}{|c|}{ PANEL B - Monthly excess returns } \\
\hline VICE fund & 84 & $31 / 10 / 2002$ & $30 / 09 / 2009$ & 3.156 & 16.287 & -1.158 & 4.920 & 31.664 & 0.000 & -0.161 & 0.087 \\
\hline SRI portfolio & 192 & 29/10/1993 & $30 / 09 / 2009$ & -1.112 & 15.681 & -0.989 & 5.892 & 98.207 & 0.000 & -0.212 & 0.125 \\
\hline MRI portfolio & 192 & $29 / 10 / 1993$ & $30 / 09 / 2009$ & -1.883 & 15.618 & -0.900 & 5.271 & 67.195 & 0.000 & -0.208 & 0.120 \\
\hline S\&P500 & 192 & $29 / 10 / 1993$ & $30 / 09 / 2009$ & 3.115 & 15.595 & -0.936 & 4.716 & 51.628 & 0.000 & -0.186 & 0.091 \\
\hline
\end{tabular}




\section{Table 2 - CAPM based performance estimates}

Panel A of this table presents regression estimates, based on daily excess returns, for the Vice fund and equally weighted portfolios of SRI and MRI funds computed using the S\&P500 index as the benchmark. Alphas expressed in percentage, systematic risk (Beta) and the adjusted coefficient of determination ( $\mathrm{R}^{2} \mathrm{adj}$.) are reported. Regression residuals are tested using the Jarque-Bera test for normality, the White (1980) test for heteroscedasticity if the residuals are not normal, the Breusch and Pagan (1979) for heteroscedasticity if the residuals are normal and the Durbin-Watson test for autocorrelation. Standard errors are corrected, whenever appropriate, for the presence of heteroscedasticity using the correction of Cribari-Neto (2004) which performs better in smaller samples than White (1980), or for the presence of autocorrelation and heteroscedasticity using the procedure suggested by Newey and West (1994). The number of individual SRI and MRI funds presenting statistically significant positive, not different from zero and negative alphas are also reported. Panel B reports the same type of estimates obtained using monthly excess returns.

\begin{tabular}{|c|c|c|c|c|}
\hline & $\alpha$ & $\beta$ & $R^{2}$ adj. & JB prob. \\
\hline \multicolumn{5}{|c|}{ PANEL A - Daily excess returns } \\
\hline VICE fund & 0.006 & $0.651 * * *$ & $69.7 \%$ & 0.000 \\
\hline SRI portfolio & $-0.014^{* * *}$ & $0.881^{* * *}$ & $93.0 \%$ & 0.000 \\
\hline № of $+/ 0 /-$ alphas & $0 / 36 / 2$ & & & \\
\hline MRI portfolio & $-0.017 * * *$ & $0.860^{* * *}$ & $87.6 \%$ & 0.000 \\
\hline № of $+/ 0 /-$ alphas & $0 / 11 / 2$ & & & \\
\hline \multicolumn{5}{|c|}{ PANEL B - Monthly excess returns } \\
\hline VICE fund & 0.053 & $0.877^{* * *}$ & $68.0 \%$ & 0.172 \\
\hline SRI portfolio & $-0.337^{* * *}$ & $0.939 * * *$ & $87.2 \%$ & 0.000 \\
\hline № of $+/ 0 /-$ alphas & $1 / 35 / 1$ & & & \\
\hline MRI portfolio & $-0.394^{* * *}$ & $0.912^{* * *}$ & $82.8 \%$ & 0.000 \\
\hline № of $+10 /$ - alphas & $0 / 11 / 2$ & & & \\
\hline
\end{tabular}

*** Statistically significant at the $1 \%$ level

** Statistically significant at the 5\% level

* Statistically significant at the $10 \%$ level 


\section{Table 3 - Carhart 4-factor model performance estimates}

Panel A of this table presents regression estimates, based on daily excess returns, for the Vice fund and equally weighted portfolios of SRI and MRI funds computed using the Carhart 4-factor model. Alphas expressed in percentage, regression coefficients on Market, Value, Size and Momentum factors, the adjusted coefficient of determination $\left(\mathrm{R}^{2} \mathrm{adj}\right.$.) and the probability value of the Wald test on the hypothesis of additional factors to the market factor (S\&P500) being equal to zero are reported. Regression residuals are tested using the Jarque-Bera test for normality, the White (1980) test for heteroscedasticity if the residuals are not normal, the Breusch and Pagan (1979) for heteroscedasticity if the residuals are normal and the Durbin-Watson test for autocorrelation. Standard errors are corrected, whenever appropriate, for the presence of heteroscedasticity using the correction of Cribari-Neto (2004) which performs better in smaller samples than White (1980), or for the presence of autocorrelation and heteroscedasticity using the procedure suggested by Newey and West (1994). The number of individual SRI and MRI funds presenting statistically significant positive, not different from zero and negative alphas are also reported. Panel $B$ reports the same type of estimates obtained using monthly excess returns.

\begin{tabular}{|c|c|c|c|c|c|c|c|c|}
\hline & $\alpha$ & Market & Value & Size & Mom & $\mathrm{R}^{2}$ adj. & JB prob. & Wald \\
\hline \multicolumn{9}{|c|}{ PANEL A - Daily excess returns } \\
\hline VICE fund & 0.008 & $0.726 * * *$ & $-0.093 * *$ & $0.096 * *$ & $0.134^{\star * *}$ & $72.5 \%$ & 0.000 & 0.000 \\
\hline SRI portfolio & $-0.017^{* * *}$ & $0.900 * * *$ & $0.047^{* * *}$ & $0.311^{\star * \star}$ & $-0.051^{* * *}$ & $95.7 \%$ & 0.000 & 0.000 \\
\hline NNo of $+/ 0 /-$ alphas & $0 / 33 / 5$ & & & & & & & \\
\hline MRI portfolio & $-0.020^{* \star *}$ & $0.891^{* * *}$ & 0.012 & $0.297^{* * *}$ & 0.013 * & $89.9 \%$ & 0.000 & 0.000 \\
\hline № of $+/ 0 /-$ alphas & $0 / 9 / 4$ & & & & & & & \\
\hline \multicolumn{9}{|c|}{ PANEL B - Monthly excess returns } \\
\hline VICE fund & 0.019 & $0.910 * * *$ & 0.044 & 0.209 & 0.108 * & $69.1 \%$ & 0.140 & 0.115 \\
\hline SRI portfolio & $-0.366^{* * *}$ & $0.900 * * *$ & 0.061 * & $0.243^{* * *}$ & $-0.081 * * *$ & $91.2 \%$ & 0.000 & 0.000 \\
\hline № of $+/ 0 /$ - alphas & $0 / 32 / 5$ & & & & & & & \\
\hline MRI portfolio & $-0.449^{* * *}$ & $0.901 * * *$ & 0.040 & $0.217^{* * *}$ & -0.013 & $85.3 \%$ & 0.000 & 0.000 \\
\hline NNo of $+/ 0 /-$ alphas & $0 / 8 / 5$ & & & & & & & \\
\hline
\end{tabular}

*** Statistically significant at the $1 \%$ level

** Statistically significant at the 5\% level

* Statistically significant at the $10 \%$ level 


\section{Table 4 - MS-CCAPM based performance estimates}

Panel A of this table presents regression estimates, based on daily excess returns, for the Vice fund and equally weighted portfolios of SRI and MRI funds computed using the MS-CCAPM. Alphas, expressed in percentage, and systematic risk (Beta) estimates for the two different volatility market regimes (Low volatility and High volatility) are reported. Standardized residuals are tested for normality using the Doornik and Hansen (1994) test, and also for autocorrelated conditional heteroscedasticity using Engle's (1982) ARCH test. Results of these tests are reported, as well as their associated p-value. The number of individual SRI and MRI funds presenting statistically significant positive, not different from zero and negative alphas are also reported. Panel B reports the same type of estimates obtained using monthly excess returns.

\begin{tabular}{|c|c|c|c|c|c|c|}
\hline & $\alpha$ Low & $\alpha$ High & $\beta$ Low & $\beta$ High & Norm test & $\mathrm{ARCH}$ \\
\hline \multicolumn{7}{|c|}{ PANEL A - Daily excess returns } \\
\hline VICE fund & 0.029 ** & -0.045 * & $0.809 * \star \star$ & 0.632 *** & Non-normal 0.0004 & No ARCH 0.3841 \\
\hline SRI portfolio & 0.001 & $-0.015^{* *}$ & $0.863^{* \star *}$ & $0.885^{* * *}$ & Non-normal 0.0000 & No ARCH 0.4545 \\
\hline № of $+/ 0 /-$ alphas & $5 / 32 / 1$ & $4 / 31 / 3$ & & & & \\
\hline MRI portfolio & 0.001 & -0.011 * & $0.881^{\star \star \star}$ & $0.867^{\star \star \star}$ & Non-normal 0.0000 & $\mathrm{ARCH} 0.0000$ \\
\hline № of $+/ 0 /$ - alphas & $2 / 10 / 1$ & $0 / 13 / 0$ & & & & \\
\hline \multicolumn{7}{|c|}{ PANEL B - Monthly excess returns } \\
\hline VICE fund & $0.656^{\star \star \star}$ & $-1.010^{\star *}$ & $1.054^{* \star \star}$ & $0.877^{\star \star \star}$ & Normal 0.7616 & No ARCH 0.0690 \\
\hline SRI portfolio & $-0.228^{* \star *}$ & -0.165 & $0.926^{\star \star \star *}$ & 0.956 *** & Non-normal 0.0470 & No ARCH 0.5428 \\
\hline № of $+/ 0 /-$ alphas & $3 / 25 / 9$ & $8 / 27 / 2$ & & & & \\
\hline MRI portfolio & $-0.238^{\star * *}$ & -0.256 * & $0.969 * \star \star$ & $0.880^{* \star *}$ & Normal 0.1411 & No ARCH 0.5127 \\
\hline № of $+/ 0 /-$ alphas & $1 / 10 / 2$ & $1 / 11 / 1$ & & & & \\
\hline
\end{tabular}

*** Statistically significant at the $1 \%$ level

** Statistically significant at the $5 \%$ level

* Statistically significant at the $10 \%$ level 


\section{Table 5 - MS-CCAPM based performance estimates for the same period as the Vice fund (September 2002 to October 2009)}

Panel A of this table presents regression estimates, based on daily excess returns, for the Vice fund and equally weighted portfolios of SRI and MRI funds computed using the MS-CCAPM. Alphas, expressed in percentage, and systematic risk (Beta) estimates for the two different volatility market regimes (Low volatility and High volatility) are reported. Standardized residuals are tested for normality using the Doornik and Hansen (1994) test, and also for autocorrelated conditional heteroscedasticity using Engle's (1982) ARCH test. Results of these tests are reported, as well as their associated p-value. The number of individual SRI and MRI funds presenting statistically significant positive, not different from zero and negative alphas are also reported. Panel B reports the same type of estimates obtained using monthly excess returns.

\begin{tabular}{|c|c|c|c|c|c|c|}
\hline & $\alpha$ Low & $\alpha$ High & $\beta$ Low & $\beta$ High & Norm test & $\mathrm{ARCH}$ \\
\hline \multicolumn{7}{|c|}{ PANEL A - Daily excess returns } \\
\hline VICE fund & $0.031^{* * *}$ & $-0.078^{* * *}$ & $0.807^{* * *}$ & $0.619^{* * *}$ & Non-normal 0.0002 & No ARCH 0.5308 \\
\hline SRI portfolio & 0.000 & $-0.019 *$ & $0.965^{* * *}$ & $0.912^{* * *}$ & Non-normal 0.0000 & ARCH 0.0001 \\
\hline № of $+/ 0 /$ - alphas & $4 / 30 / 4$ & $3 / 33 / 2$ & & & & \\
\hline MRI portfolio & 0.003 & -0.013 & $1.002^{* * *}$ & $0.866^{* * *}$ & Non-normal 0.0000 & No ARCH 0.0773 \\
\hline № of $+/ 0 /$ - alphas & $3 / 9 / 1$ & $0 / 12 / 1$ & & & & \\
\hline \multicolumn{7}{|c|}{ PANEL B - Monthly excess returns } \\
\hline VICE fund & $0.656 * *$ & $-1.010^{* *}$ & $1.054^{* * *}$ & $0.877^{* * *}$ & Normal 0.7616 & No ARCH 0.0690 \\
\hline SRI portfolio & $-0.309^{* \star \star}$ & 0.116 & $1.090^{* * *}$ & $1.062 * * *$ & Normal 0.8563 & No ARCH 0.7298 \\
\hline № of $+/ 0 /$ - alphas & $3 / 25 / 9$ & $6 / 17 / 4$ & & & & \\
\hline MRI portfolio & -0.142 & -0.097 & $1.093^{* * *}$ & $0.940^{* * *}$ & Normal 0.2119 & No ARCH 0.7887 \\
\hline № of $+/ 0 /$ - alphas & $3 / 8 / 1$ & $3 / 9 / 0$ & & & & \\
\hline
\end{tabular}

*** Statistically significant at the $1 \%$ level

** Statistically significant at the 5\% level

* Statistically significant at the $10 \%$ level 


\section{Appendix 1}

\begin{tabular}{|c|c|c|}
\hline $\begin{array}{l}\text { Datastream } \\
\text { code }\end{array}$ & Fund designation (as it appears in Datastream) & $\begin{array}{l}\text { Type of } \\
\text { fund }\end{array}$ \\
\hline 152915 & AMANA MUT.FUND.TST.GW. FD. . TOT RETURN IND ( USD) & MRI \\
\hline 325067 & AMANA MUT.FUND.TST.INC. FD. . TOT RETURN IND ( USD) & MRI \\
\hline $41363 \mathrm{~T}$ & APPLESEEDFUND . TOT RETURN IND ( USD) & SRI \\
\hline 543748 & ARIEL APPREC.FD. . TOT RETURN IND ( USD) & SRI \\
\hline $31283 N$ & ARIEL FOCUS FD. . TOT RETURN IND ( USD) & SRI \\
\hline 511216 & ARIEL FUND . TOT RETURN IND ( USD) & SRI \\
\hline $13899 \mathrm{R}$ & AVE MARIACATH.VALUES FD. . TOT RETURN IND ( USD) & MRI \\
\hline $27000 P$ & AVE MARIAGROWTH FUND . TOT RETURN IND ( USD) & MRI \\
\hline $35915 \mathrm{~L}$ & AVE MARIAOPPORTUNITY FUND . TOT RETURN IND ( USD) & MRI \\
\hline $26555 D$ & AZZAD ETHICAL MID CP.FD. . TOT RETURN IND ( USD) & SRI \\
\hline $31290 W$ & CALVERT AGRSIV.ALOCN.FD. CL.A . TOT RETURN IND ( USD) & SRI \\
\hline 867003 & CALVERT CAP.AC.FD.CL.A . TOT RETURN IND ( USD) & SRI \\
\hline $30812 K$ & CALVERT CNSV.ALOCN.FUND CL.A . TOT RETURN IND ( USD) & SRI \\
\hline $13262 \mathrm{~J}$ & CALVERT LGE.CAP.GW.FD. CL.A SHS. . TOT RETURN IND ( USD) & SRI \\
\hline $29572 T$ & CALVERT MID.CAP.VAL.FD. CL.A . TOT RETURN IND ( USD) & SRI \\
\hline $30812 \mathrm{~L}$ & CALVERT MODERATE ALOCN. FD.CL.A . TOT RETURN IND ( USD) & SRI \\
\hline 674104 & CALVERT NEW VIS.SML.CAP FD.CL.A . TOT RETURN IND ( USD) & SRI \\
\hline 264416 & CALVERT SCL.IDX.FD.CL. 'I' . TOT RETURN IND ( USD) & SRI \\
\hline 29572R & CALVERT SML.CAP.VAL.CL.A. TOT RETURN IND ( USD) & SRI \\
\hline 151147 & CALVERT SOCIAL IF.EQ.CL. C . TOT RETURN IND ( USD) & SRI \\
\hline $30164 \mathrm{~V}$ & CNI CHARTER FDS. AHA SCLY.RESP.EQ.FD.CL.I . TOT RETURN IND ( USD) & SRI \\
\hline 889042 & DOMINI INSTL.SOCIAL EQ. FD. . TOT RETURN IND ( USD) & SRI \\
\hline 312402 & DOMINI SOCIAL EQ.FD. . TOT RETURN IND ( USD) & SRI \\
\hline 311557 & FLEX.FUNDS THE TOR. UTILS.FD. . TOT RETURN IND ( USD) & SRI \\
\hline $50628 \mathrm{C}$ & GABELLI SRI GRN.FD.CL.A . TOT RETURN IND ( USD) & SRI \\
\hline 878705 & GREEN CENTURY EQ.FUND . TOT RETURN IND ( USD) & SRI \\
\hline $30875 T$ & INTEGRITYGW.I\& INC.FD . TOT RETURN IND ( USD) & SRI \\
\hline 131604 & LKCM AQUINAS GW.FD. . TOT RETURN IND ( USD) & MRI \\
\hline 360813 & LKCM AQUINAS SML.CP.FD. . TOT RETURN IND ( USD) & MRI \\
\hline 360812 & LKCM AQUINAS VAL.FD. . TOT RETURN IND ( USD) & MRI \\
\hline 515952 & LUTHERAN BHOOD.FD.CL.A DEAD . MERGER 510632 . TOT RETURN IND ( USD) & MRI \\
\hline 130047 & MMA PRAXIS CORE STOCK FD.CL.B . TOT RETURN IND ( USD) & SRI \\
\hline 504890 & MMA PRAXIS GW.IDX.FD. CL.A . TOT RETURN IND ( USD) & SRI \\
\hline $50490 \mathrm{C}$ & MMA PRAXIS SMCP.FD.CL.A . TOT RETURN IND ( USD) & SRI \\
\hline $14357 \mathrm{~F}$ & MMA PRAXIS VAL.IDX.FD. CL.A SHS. . TOT RETURN IND ( USD) & SRI \\
\hline 873982 & NEUBERGER \& BERMAN SOCIALLY RESPONSIVE FD. . TOT RETURN IND ( USD) & SRI \\
\hline 542145 & NEW ALTERNATIVES FD. . TOT RETURN IND ( USD) & SRI \\
\hline 274791 & NEW COVENANT GW.FD. . TOT RETURN IND ( USD) & MRI \\
\hline $35722 \mathrm{~T}$ & PARNASSUSEQ.INC.FD. INSTL. . TOT RETURN IND ( USD) & SRI \\
\hline 517387 & PARNASSUSFD. . TOT RETURN IND ( USD) & SRI \\
\hline $30886 \mathrm{~F}$ & PARNASSUSMID CP.FD. . TOT RETURN IND ( USD) & SRI \\
\hline $30886 \mathrm{H}$ & PARNASSUSSML.CP.FD. . TOT RETURN IND ( USD) & SRI \\
\hline $30886 \mathrm{~K}$ & PARNASSUSWORKPLACE FD. . TOT RETURN IND ( USD) & SRI \\
\hline $51231 \mathrm{~N}$ & PAX WLD.WOMEN'S EQ.FD. IVDL.INVR.CL. . TOT RETURN IND ( USD) & SRI \\
\hline 674675 & PAX WORLDGW.FD. . TOT RETURN IND ( USD) & SRI \\
\hline 687456 & SENTINEL SUST.CORE OPPS. FD.CL.A . TOT RETURN IND ( USD) & SRI \\
\hline 15434E & THE CATH.EQ.FD. CL.A . TOT RETURN IND ( USD) & MRI \\
\hline 683745 & THE NOAH INV.GP.NOAH FD. DEAD . MERGED W/26198T . TOT RETURN IND ( US & MRI \\
\hline 26198Q & TIMOTHY PLAN AGRSIV.GW. FD.CL.A . TOT RETURN IND ( USD) & MRI \\
\hline $26188 U$ & VICE FUND . TOT RETURN IND ( USD) & VICE \\
\hline 699844 & WALDEN SOCIAL EQ.FD. . TOT RETURN IND ( USD) & SRI \\
\hline 13857D & WINSLOW GREEN GW.FUND. INVR.CL. . TOT RETURN IND ( USD) & SRI \\
\hline
\end{tabular}

